\title{
Distribution of emergency operations and trauma in a Swedish hospital: need for reorganisation of acute surgical care?
}

Fawzi al-Ayoubi, Helen Eriksson, Pär Myrelid, Conny Wallon and Peter Andersson*

\begin{abstract}
Background: Subspecialisation within general surgery has today reached further than ever. However, on-call time, an unchanged need for broad surgical skills are required to meet the demands of acute surgical disease and trauma. The introduction of a new subspecialty in North America that deals solely with acute care surgery and trauma is an attempt to offer properly trained surgeons also during on-call time. To find out whether such a subspecialty could be helpful in Sweden we analyzed our workload for emergency surgery and trauma.
\end{abstract}

Methods: Linköping University Hospital serves a population of 257 000. Data from 2010 for all patients, diagnoses, times and types of operations, surgeons involved, duration of stay, types of injury and deaths regarding emergency procedures were extracted from a prospectively-collected database and analyzed.

Results: There were 2362 admissions, 1559 emergency interventions; 835 were mainly abdominal operations, and 724 diagnostic or therapeutic endoscopies. Of the 1559 emergency interventions, 641 (41.1\%) were made outside office hours, and of 453 minor or intermediate procedures (including appendicectomy, cholecystectomy, or proctological procedures) 276 (60.9\%) were done during the evenings or at night. Two hundred and fifty-four patients were admitted with trauma and $29(11.4 \%)$ required operation, of whom general surgeons operated on eight (3.1\%). Thirteen consultants and 11 senior registrars were involved in 138 bowel resections and 164 cholecystectomies chosen as index operations for standard emergency surgery. The median (range) number of such operations done by each consultant was $6(3-17)$ and 6 (1-22). Corresponding figures for senior registrars were $7(0-11)$ and $8(1-39)$.

Conclusion: There was an uneven distribution of exposure to acute surgical problems and trauma among general surgeons. Some were exposed to only a few standard emergency interventions and most surgeons did not operate on a single patient with trauma. Further centralization of trauma care, long-term positions at units for emergency surgery and trauma, and subspecialisation in the fields of emergency surgery and trauma, might be options to solve problems of low volumes.

Keywords: Acute care surgery, Trauma, Centralization, Subspecialisation

\footnotetext{
* Correspondence: ps1@algonet.se

Unit for Acute Care Surgery and Trauma, Department of Surgery, Linköping

University Hospital, S-581 85, Linköping, Sweden
}

\section{() Biomed Central




\section{Background}

Subspecialisation in what has always been called general surgery has in most countries (including Sweden) been carried further than ever during the past decade resulting in breast, endocrine, colorectal, and upper gastrointestinal (GI) surgery being almost independent entities. Vascular surgery has become a specialty on its own. This has resulted from, among other things, more strict regulation and the recording of actual hours worked. Carefully regulated use of compensation leave in accordance with the European Working Time Directive has resulted in there being even less time than before for traditional general surgical training [1]. It has become necessary to focus on a narrow field of surgery if sufficient theoretical and practical knowledge is to be acquired within a reasonable period of time. This must be maintained to meet the quality demands for surgical practice that are raised by the profession, the patients, and by health care providers for elective surgery.

Outside office hours, however, there is still a need for broad and varied surgical competence in dealing with acute illness and trauma. In Sweden the surgical profession has attempted to solve this by offering, for consultant surgeons on call, specific courses within each subspecialty that focus on emergency conditions; they also offer courses in trauma care. Elsewhere, for example in the USA and Canada, attempts to solve similar problems have resulted in the introduction of the new surgical subspecialty "acute care surgery" [2,3]. One of its prerequisites as a distinct specialty is the establishment of certain units within hospitals that care for patients with acute surgical conditions and trauma. Several surgical departments in Sweden have already introduced such units for acute care surgery and others intend to do so. So far the need for subspecialisation in acute care surgery and trauma, such as in North America, for surgeons staffing these units, has been discussed only casually in Sweden. To address the issue of whether such subspecialisation could be advantageous in Sweden we analyzed the surgical activities at the unit for Acute Care Surgery and Trauma (ACST), Department of Surgery, Linköping University Hospital, during one year.

\section{Methods}

Data about all patients treated in the ACST unit from Jan. $1^{\text {st }}$ to Dec. $31^{\text {st }}, 2010$ included diagnoses, operations, duration of operation, surgeon involved, duration of stay, readmission, trauma, and death were extracted from a prospectively collected database including basic perioperative and postoperative information about all patients treated at the Department of Surgery. The study was a clinical quality-control study approved by the Head of the Department of Surgery, Linköping University Hospital, Linköping, Sweden. Descriptive data are given as number (\%) without further statistical analysis. They were handled and analyzed on Statistical software version 9.0 (Statsoft Inc. Tulsa, OK, USA).

Linköping University Hospital is the only hospital that serves a population of 257000 for emergency surgery and trauma. It also serves a further 835000 as a secondary and tertiary referral centre, mainly for elective surgery and advanced trauma care such as neurological trauma or burns. The ACST has round-the-clock responsibility for all acute admissions and emergency operations and endoscopies in the surgical department, and provides acute consultations within the hospital and the emergency department, the latter mainly staffed by emergency physicians. It has at its disposal one dedicated operating theatre shared with obstetrics and gynaecology for acute cases, a surgical acute care ward with 28 beds, and an outpatient clinic two afternoons a week. All local and regionally referred trauma except for isolated neurological trauma are primarily dealt with in the ACST. Elective procedures are strictly separated from the activities of the ACST and dealt with by the units for colorectal, upper GI, and endocrine surgery.

During office hours the ACST is staffed by three, or sometimes four, senior registrars or consultants, usually one junior registrar, and one or two house officers all of whom are working exclusively in the unit. The permanent surgical staff consists of two full time consultants, one half-time consultant, two senior registrars, and one junior registrar with a long-term appointment. The remaining staff needed to cover vacations and compensation leave are met by a weekly rota of surgeons who rotate from other units within the department of surgery for either one or two weeks; this arrangement also aims to increase exposure to emergency surgery and trauma during the day to all surgeons in the department. Out of office hours there is a senior registrar on call in the hospital. A consultant who trained as a general surgeon, but specialized in either colorectal, upper-GI, or endocrine surgery, is on call outside the hospital and is prepared to intervene at short notice. Care for vascular emergencies is provided separately by vascular surgeons.

\section{Results}

\section{Emergency surgery}

During 2010 there were 2362 admissions (1175 (49.7\%) of whom were men) to the ACST with a median age of 62 years (16-100). Median (range) duration of stay was 2 days (1-118). One-hundred and ninety-five patients were readmitted within 30 days of discharge, and 32 died during their stay of whom 19 had been operated on. The most common diagnosis was benign biliary disease requiring surgery or therapeutic ERCP (endoscopic retrograde cholangiopancreaticography) in $76.2 \%$ of cases. Proctologic disease was along with appendicitis the diagnosis where 
the largest part of patients was subjected to surgical intervention; $97.2 \%$ and $92.5 \%$ respectively. After trauma and non-specific abdominal pain, patients diagnosed with small bowel obstruction, pancreatitis or diverticular disease of the colon represented diagnoses where least part of the patients required intervention (Table 1).

The ACST provided care for 126 patients who required treatment in the intensive care unit (ICU) with a median stay of 2 days (1-31); the cause was trauma in 44 cases. A total of 1559 emergency interventions were made, which consisted of 835 mainly abdominal operations and 724 diagnostic or therapeutic endoscopies. These included, for example, hemostasis, removal of polyps, or ERCP with sphincterotomy. Twenty patients (2.4\%) were reoperated on within 30 days. The most common intervention was diagnostic endoscopy by means of upper-GI endoscopy or colonoscopy, and the most common operations were appendicectomy, cholecystectomy, and proctological examinations under anesthesia with interventions. A total of 1559 emergency interventions 641 (41.1\%) were done out of office hours. Most common minor and intermediate operations (appendicectomy, cholecystectomy, and proctological interventions) were done during the evening or at night (between 1700 and 0800) (276/453, 60.9\%) as opposed to major procedures such as colectomies or colonic resections, fewer of which were done during that time (33/80, 41.2\%). Corresponding figures for therapeutic endoscopy during the evening or at night were 11 of 217
(5.1\%), all of which were prompted by upper gastrointestinal bleeding and necessitated endoscopic hemostasis (Table 2).

\section{Trauma}

The trauma team was activated 181 times, and 254 patients were admitted (Table 1). The most common mechanism of injury was a fall $(n=126)$, and the second was traffic crashes $(n=69)$ followed by sport and leisure activities $(n=23)$, and assaults $(n=23)$. The vast majority of trauma-cases were the result of blunt trauma, only four injuries being penetrating ones caused by a knife or firearm. Of those admitted, 29 (11.4\%) required a total of 40 operations. General surgeons were involved in only eight $(3.1 \%)$ of these patients, specifically in exploratory laparotomy $\mathrm{n}=5$ (enterorrhaphy $\mathrm{n}=2$, splenectomy $\mathrm{n}=1$, and no abnormality found $\mathrm{n}=2$ ), thoracotomy $\mathrm{n}=1$ (no abnormality found), and cervical injury $\mathrm{n}=2$ (ligation of external and internal carotid arteries). The remaining interventions were covered by orthopedics, neurosurgery, or ear nose and throat consultants. Forty-four patients (17.3\%) required intensive care and were treated under the care of the general surgeons for at least the first 24 hours according to the routines for multitrauma care at the hospital.

\section{Distribution of interventions among surgeons}

Most of the most common operations during office hours and while on call were done by either a senior registrar

Table 1 Most common diagnoses at ACST 2010

\begin{tabular}{|c|c|c|c|c|}
\hline Diagnoses & $\begin{array}{l}\text { No. (\%) of } \\
\text { admissions }\end{array}$ & $\begin{array}{l}\text { Total No. of main operations } \\
\text { including reoperations }\end{array}$ & $\begin{array}{l}\text { Total No.of } \\
\text { endoscopies }\end{array}$ & $\begin{array}{l}\text { Percentage of patients in need of } \\
\text { surgical or endoscopic procedures }\end{array}$ \\
\hline Benign biliary disease & $282(12.0)$ & 152 & 105 & 76.2 \\
\hline Trauma & $254(10.8)$ & 29 & 0 & 11.4 \\
\hline Appendicitis & $214(9.1)$ & 199 & 0 & 92.5 \\
\hline Abdominal pain & $197(8.3)$ & 9 & 26 & 16.2 \\
\hline Colonic diverticulitis & $166(7.0)$ & 19 & 70 & 39.2 \\
\hline Malignant or possibly malignant tumours & $162(6.8)$ & 61 & 106 & 75.3 \\
\hline $\begin{array}{l}\text { Acid related disease (oesophagitis, } \\
\text { bleeding ulcer or perforation) }\end{array}$ & $147(6.2)$ & 26 & 171 & 93.2 \\
\hline Small bowel obstruction & $137(5.8)$ & 44 & 8 & 31.4 \\
\hline $\begin{array}{l}\text { Postoperative complications } \\
\text { (as cause of readmission) }\end{array}$ & $104(4.4)$ & 29 & 35 & 59.6 \\
\hline Pancreatitis & $97(4.1)$ & 18 & 24 & 39.2 \\
\hline Proctological disease & $72(3.0)$ & 65 & 13 & 97.2 \\
\hline Abdominal hernia & $57(2.4)$ & 44 & 0 & 78.9 \\
\hline Inflammatory bowel disease & $36(1.6)$ & 12 & 10 & 63.8 \\
\hline Miscellaneous & $361(15.3)$ & 105 & 139 & 47.6 \\
\hline Missing diagnoses & $76(3.2)$ & 23 & 17 & 43.4 \\
\hline Total & 2362 & 835 & 724 & 50.7 \\
\hline
\end{tabular}


Table 2 Most common invasive procedures at ACST 2010

\begin{tabular}{|c|c|c|c|c|c|}
\hline Operations & $\begin{array}{c}\text { Office hours } \\
0800-1700\end{array}$ & $\begin{array}{c}\text { Weekend } \\
0800-1700\end{array}$ & $\begin{array}{c}\text { Evening } \\
1700-2400 \\
\end{array}$ & $\begin{array}{c}\text { Night } \\
0000-0800 \\
\end{array}$ & Total No. \\
\hline Diagnostic endoscopy & 422 & 41 & 31 & 13 & 507 \\
\hline Therapeutic endoscopy & 189 & 17 & 7 & 4 & 217 \\
\hline Appendicectomy & 33 & 12 & 91 & 78 & 214 \\
\hline Cholecystectomy & 69 & 41 & 50 & 4 & 164 \\
\hline Proctological procedure & 15 & 7 & 32 & 21 & 75 \\
\hline Colonic resection & 27 & 5 & 18 & 14 & 64 \\
\hline Hernia repair & 17 & 1 & 8 & 11 & 37 \\
\hline Reoperation for complication & 15 & 2 & 13 & 6 & 36 \\
\hline Division of adhesions & 11 & 2 & 10 & 4 & 27 \\
\hline Exploratory laparotomy & 6 & 3 & 13 & 3 & 25 \\
\hline Stoma procedure & 13 & 3 & 6 & 2 & 24 \\
\hline Gastroduodenal intervention & 11 & 3 & 3 & 5 & 22 \\
\hline Subtotal colectomy & 13 & 2 & 0 & 1 & 16 \\
\hline Small bowel resection & 5 & 2 & 5 & 3 & 15 \\
\hline Diagnostic laparoscopy & 4 & 2 & 3 & 5 & 14 \\
\hline Miscellaneous & 68 & 16 & 11 & 7 & 102 \\
\hline \multirow[t]{2}{*}{ Total } & 918 & 159 & 301 & 181 & 1559 \\
\hline & (58.9\%) & $(10.2 \%)$ & (19.3\%) & (11.6\%) & (100\%) \\
\hline
\end{tabular}

Data are number of patients divided by time of day.

$(\mathrm{n}=11)$ or a consultant $(\mathrm{n}=13)$ as the main surgeon (diagnostic gastroscopy (70.8\%), appendicectomy (83.2\%), hernia repair (83.8\%), cholecystectomy (84.8\%), and colonic or small-bowel resection, including formation of a stoma (94.9\%). The corresponding figures for the junior registrars in the department $(n=4)$ as main surgeon were $29.2 \%, 16.8 \%, 16.2 \%, 15.2 \%$ and $5.1 \%$, respectively (Figure 1).

On call service outside the hospital and the resultant potential exposure to emergency surgery during on call time were equally divided during the year among 13 consultants in general surgery whose subspecialties were colorectal, upper-GI, and endocrine surgery. The commitment of time to emergency surgical interventions during office hours differed among consultants as a result of their variable rotational commitments at the ACST. Some of the consultants did not actually serve there at all, or only in a limited way, while one of them spent most of his time there. For common intermediate emergency interventions such as colonic or small-bowel resections, including stoma surgery $(n=138)$, or gallbladder surgery $(n=164)$, the median number of operations done by each individual consultant during the year (either as the main or assisting surgeon) was $6(3-17)$ and $6(1-22)$, respectively. The corresponding number for the 11 senior registrars on call in the hospital, of whom three spent their days in the ACST, was $7(0-11)$ and $8(1-39)$, respectively; the highest figures were those assigned to the ACST.

\section{Discussion}

The current trend for general surgery in Sweden towards greater subspecialisation within units, and also towards a reduction in the number of facilities that provide acute health care, including the number of surgical departments, is clear [4]. If we focus more on excellence among surgeons, each one who works within a narrowly-defined elective surgical field (while at the same time being governed by stricter regulation of working hours specified by the European Union directives) has ever less time available to gain competence within the broad area of general surgery. Emergency surgery and traumatology, still the responsibility of most surgeons during their on call time, requires sufficient training in general surgery.

Our simple descriptive data about emergency surgery and the treatment of trauma during a single year at the University Hospital in Linköping show that more than half the patients have some form of intervention from a relatively large number of surgeons. More than $40 \%$ of emergency operations in our hospital are done out of office hours, commonly during evenings and nights when informal support from skilled colleagues may be hard to find. It can be claimed that most procedures are simple but this is not always true for, for example, intestinal resections, bleeding duodenal ulcers, or even cholecystectomies for acute cholecystitis. Ideally fewer patients should be operated on during the evening or 


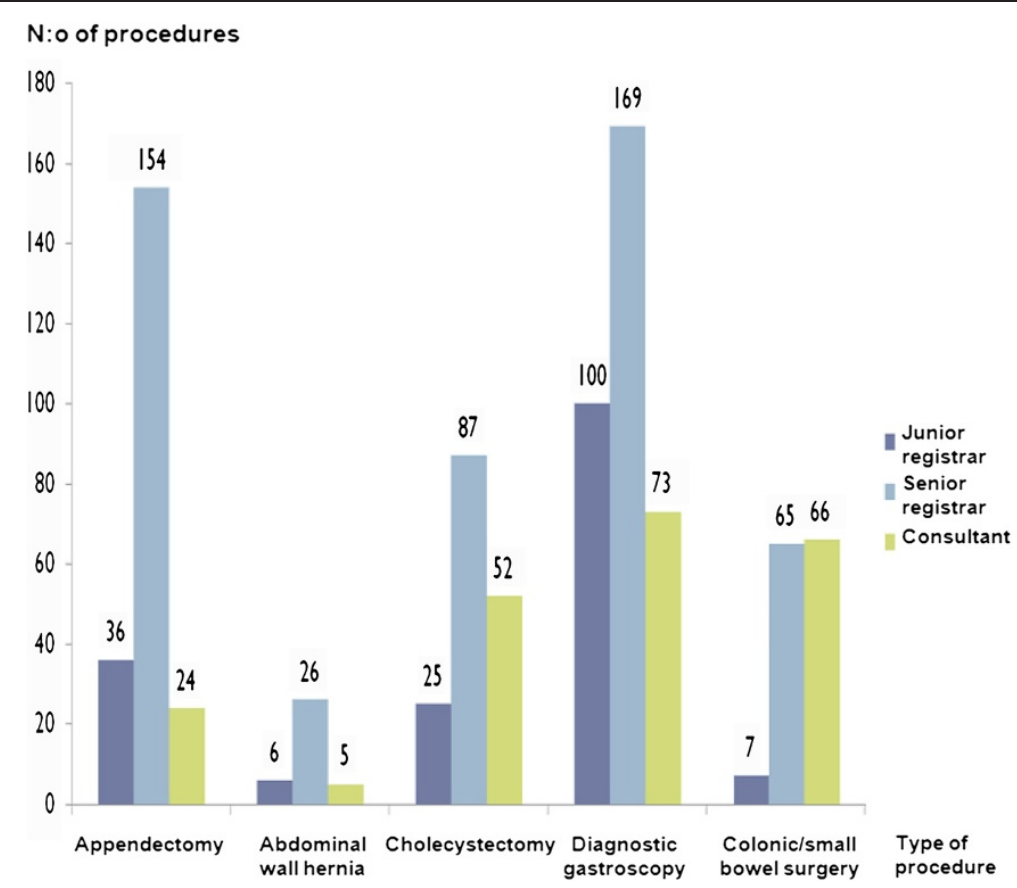

Figure 1 Some of the most common invasive surgical operations or endoscopic procedures done at the unit for Acute Surgery and Trauma during $\mathbf{2 0 1 0}$ divided after the level of experience of the operating surgeon.

night than is now current, almost $31 \%$ being treated. Only about half of them really need emergent operations, while the rest actually present day-time with less emergent indications, i.e. urgent, that can wait up to six hours or more. One of the reasons for the disproportion between night and day is the irrational nature of acute surgery which in the light of increasing demands for effective use of health-care resources results in difficulties to assign more than one operating theatre during the day. This ultimately delays surgery to inconvenient hours.

Most of the most common emergencies are dealt with by surgeons who are specialists in some subspecialty, but the median number of interventions is relatively limited. The dispersion among individual surgeons is substantial, as some do only a single or even no emergency interventions such as cholecystectomies or intestinal resections during an entire year. It is also noteworthy that the annual number of therapeutic endoscopies during the evening and night shifts is small, and even if the 17 cases that are done during the weekend day shifts are added, most of them to control bleeding, there is hardly more than one case/surgeon.

Another finding is that only one in 10 of the patients treated for trauma, even in a catchment area of almost 260000 people, requires operation other than simple thoracic drainage, and only a fraction of these interventions is done by those who are seen traditionally as general surgeons. During a time as short as a single year, it might be possible that the varying numbers of interventions to some extent depend on natural fluctuations in the stream of incoming patients during specific time periods seen from the point of view of a single day, or even the whole year, but they are in the end more likely to be the result of the organization of emergency surgery and trauma. Given our existing organization it is quite clear that the exposure to emergency surgery and trauma can be quite limited.

Centralization and concentration of less common and more complex interventions for cancers such as those of the esophagus, pancreas, and rectum in designated units improves the results both in terms of complications and long-term survival [5-7]. A large volume of interventions by individual surgeons who deal with these types of diagnoses is associated with better results than those seen when surgeons deal with only a small number [8]. There are reasons to think that the same relations are likely to hold for emergency surgery, trauma, and acute endoscopy. This assumption is supported by data from designated emergency surgical care centers that have reported shorter postoperative recovery times and fewer postoperative complications for appendicitis and cholecystitis $[9,10]$. Consequently, regionalization of emergency operations to high-volume centers to improve results has previously been suggested [11].

As far as trauma management is concerned, it has been unambiguously established that mortality is lower at high-volume centers than at other centers [12]. Although Linköping University Hospital has a population 
of almost 260000 in its primary catchment area and is, in a Swedish context, a large hospital, it cannot be regarded as a high-volume trauma centre from the reported number of cases treated. A case may therefore be made that further centralization of trauma care in Sweden that results in even larger catchment areas for trauma would lead to an improvement in quality, still given the relatively small absolute number of cases.

Emergency surgery and trauma care are mainly dealt with by surgeons out of office hours. The current European Working Time Directive that restricts work to 48 hours a week, including that out of office hours, means that emergency surgery encroaches on time set aside for elective surgery. This unfortunately results in competition between elective and emergency surgery, one of which will have an adverse impact on the other. During previous decades repeated reduction in working hours for registrars in the UK has been clearly shown to have a serious impact on the opportunities for surgical training [13]. Concerns have also been raised in Norway about the quality of training for surgical residents in the light of structural changes in the health care system [14]. Our data have shown that there is all too little participation in emergency surgery and endoscopy on the part of our junior registrars, and this supports the previous findings and concerns.

\section{Conclusions}

In a Swedish university hospital setting there was an uneven distribution of exposure to acute surgical problems as well as trauma among surgeons. Some were exposed to only a few standard emergencies and most surgeons did not operate on a single patient with trauma. Residents were responsible for strikingly few emergency procedures. Dealing with acute surgery and trauma out of office hours calls for a multi-faceted knowledge of surgical approaches that is difficult to attain in the present system and will become even more difficult in the future. Further centralization of trauma care, long-term positions at units for emergency surgery and trauma and sub-specialization in the fields of emergency surgery and trauma might be solutions.

\section{Abbreviations \\ Gl: Gastrointestinal; ACST: Acute care surgery and trauma; ERCP: Endoscopic retrograde cholangiopancreaticography; ICU: Intensive care unit.}

\section{Competing interests}

None of the authors have any competing interests.

\section{Authors' contributions}

FaA contributed to the conception and design and drafted the manuscript. HE acquired all data. PM analyzed the data and drafted the manuscript. CW contributed to the conception. PA contributed to conception and design, analyzed the data, and drafted the manuscript. All authors revised the manuscript and approved the final version.
Received: 25 March 2012 Accepted: 11 September 2012

Published: 17 September 2012

\section{References}

1. Swedish Working Force Law 2011: 740, European Working Time Directive. Stockholm: Department of Justice 2012; 2003/88/EU §§ 5-9.

2. Hoyt $D, K i m ~ H$, Barrios $C$ : Acute care surgery: a new training and practice model in the United States. World J Surg 2008, 32:1630-1635.

3. Hameed M, Brenneman F, Ball C, Pagliorello J, Razek T, Parry N, and the Canadian Association of General Surgery Committee on Acute Surgery and Critical Case, et al: General surgery 2.0: the emergence of acute care surgery in Canada. Can J Surg 2010, 53:79-83.

4. Hospitals in Europe Health Care Data: http://www.hope.be/03activities/ quality_eu-hospitals/eu_country_profiles/00-hospitals_in_europesynthesis vs2011-06.pdf.

5. Branagan G, Davies N: Early impact of centralization of oesophageal cancer surgery services. Br J Surg 2004, 91:1630-1632.

6. Lemmens VE, Bosscha K, van der Schelling G, Brenninkmeijer S, Coebergh JW, de Hingh I: Improving outcome for patients with pancreatic cancer through centralization. Br J Surg 2011, 98:1455-1462.

7. Borowski DW, Bradburn DM, Mill SJ, Bharathan B, Wilson RG, Ratcliffe AA, Kelly SB, Nothern Region Colorectal Cancer Audit Group: Volume-outcome analysis of colorectal cancer-related outcomes. Br J Surg 2010, 97:1416-1430

8. Birkmeyer J, Stukel T, Siwers A, Goodney P, Wennberg D, Lucas L: Surgeon volume and operative mortality in the United States. N Engl J Med 2003, 349:2117-2127.

9. Earley A, Pryor J, Kim P, Hedrick J, Kurichi J, Minogue A, Sonnad SS, Reilly PM, Schwab CW: An acute care surgery model improves outcomes in patients with appendicitis. Ann Surg 2006, 244:498-504.

10. Lehane C, Jootun R, Bennett M, Wong S, Truskett P: Does an acute care surgery model improve the management and outcome of acute cholecystitis? ANZ J Surg 2010, 80:438-442.

11. Leppaniemi A: Emergency surgery at crossroads: it is enough to plug the hole? Scand J Surg 2007, 96:182-183.

12. Ala-Kokko TI, Ohtonen P, Koskenkari J, Laurila JJ: Improved outcome after trauma care in university-level intensive care units. Acta Anaesthesiol Scand 2009, 53:1251-1256.

13. Gurjar S, Mclrvine A: Working time changes: a raw deal for emergency operative training. Ann R Coll Surg Engl (Suppl) 2005, 87:140-141.

14. Soreide K, Glomsaker T, Soreide JA: Surgery in Norway:beyond the scalpel in the $21^{\text {st }}$ century. Arch Surg 2008, 143:1011-1016.

\section{doi:10.1186/1757-7241-20-66}

Cite this article as: al-Ayoubi et al:: Distribution of emergency operations and trauma in a Swedish hospital: need for reorganisation of acute surgical care?. Scandinavian Journal of Trauma, Resuscitation and Emergency Medicine 2012 20:66.

\section{Submit your next manuscript to BioMed Central and take full advantage of:}

- Convenient online submission

- Thorough peer review

- No space constraints or color figure charges

- Immediate publication on acceptance

- Inclusion in PubMed, CAS, Scopus and Google Scholar

- Research which is freely available for redistribution 